\title{
Carbon isotope ratios of organic compound fractions in oceanic suspended particles
}

\author{
Jeomshik Hwang ${ }^{1,2}$ and Ellen R. M. Druffel ${ }^{1}$ \\ Received 23 August 2006; revised 27 October 2006; accepted 9 November 2006; published 9 December 2006.
}

[1] To study cycling of organic fractions in the ocean, relative abundances and radio- and stable-carbon isotope measurements of total lipid extract, acid-soluble, and acidinsoluble fractions of suspended particulate organic carbon (POC) were made. Changes in relative abundances occurred mostly in the upper $1000 \mathrm{~m}$ of the water column, with a decrease in total lipid extract and the acid-soluble fraction and an increase in the acid-insoluble fraction with increasing depth. We found lower $\Delta^{14} \mathrm{C}$ values for total lipid extract and the acid-insoluble fraction than for the acid-soluble fraction, which is consistent with the previous suggestion of incorporation of dissolved organic carbon and/or resuspended sediment to POC (Druffel and Williams, 1990; Sherrell et al., 1998). The $\Delta^{14} \mathrm{C}$ values of these fractions in a given organic carbon pool must be understood in terms of acquisition of ${ }^{14} \mathrm{C}$-depleted carbon from other carbon pools in addition to aging within the reservoir. Citation: Hwang, J., and E. R. M. Druffel (2006), Carbon isotope ratios of organic compound fractions in oceanic suspended particles, Geophys. Res. Lett., 33, L23610, doi:10.1029/2006GL027928.

\section{Introduction}

[2] Nonliving organic matter in the ocean is divided into reservoirs based on operational definitions: low molecular weight dissolved organic carbon (DOC), high molecular weight (HMW) DOC, suspended particulate organic carbon (POC) with negligible sinking rate, and large, rapidly sinking POC [Verdugo et al., 2004]. Organic carbon can be converted among these forms. Sinking POC and suspended POC exchange mass by aggregation/disaggregation processes and repackaging by zooplankton [McCave, 1984; Alldredge and Jackson, 1995; Boyd et al., 1999, and references therein]. Likewise, POC is converted to DOC by various processes, such as excretion and enzymatic hydrolysis [Smith et al., 1992]. DOC can become a part of POC by gel-formation [Chin et al., 1998], adsorption and/or heterotrophic incorporation by colonizing microorganisms [Rau et al., 1986; Druffel and Williams, 1990]. Conversions among organic carbon pools are important because they affect their turnover times in the water column and availability to microorganisms.

[3] Studies have shown that marine organic carbon is a mixture of various-aged organic carbon. In general, as

\footnotetext{
${ }^{1}$ Department of Earth System Science, University of California, Irvine, California, USA.

${ }^{2}$ Now at Department of Marine Chemistry and Geochemistry, Woods Hole Oceanographic Institution, Woods Hole, Massachusetts, USA.

Copyright 2006 by the American Geophysical Union. 0094-8276/06/2006GL027928\$05.00
}

particle size decreases from POC to low molecular weight DOC, $\Delta \Delta^{14} \mathrm{C}$ values (the per mil deviation of ${ }^{14} \mathrm{C} /{ }^{12} \mathrm{C}$ ratio relative to a standard, normalized to a $\delta^{13} \mathrm{C}$ of $-25 \%$ [Stuiver and Polach, 1977]) also decrease [Guo et al., 1996]. Furthermore, within one size-fractionated organic carbon pool, organic compound classes have different $\Delta^{14} \mathrm{C}$ values [Wang et al., 1996, 1998; Hwang and Druffel, 2003; Loh et al., 2004]. Compound-specific $\Delta^{14} \mathrm{C}$ measurements of sedimentary organic carbon showed that values varied for the examined compounds within a given sediment horizon [Eglinton et al., 1997]. The ${ }^{14} \mathrm{C}$ isotopic heterogeneity of each of the size-fractionated organic carbon pools may be caused by carbon exchange among the organic carbon pools of different particle sizes and/or input from other sources.

[4] While previous studies have examined $\Delta^{14} \mathrm{C}$ signatures of organic fractions of sinking POC and HMW DOC [Wang et al., 1996, 1998; Hwang and Druffel, 2003; Loh et al., 2004], $\Delta^{14} \mathrm{C}$ signatures of the organic fractions of suspended POC in an open ocean setting remain unknown. In this paper, we present relative abundances and carbon isotopic signatures of three organic fractions, total lipid extract (TLE), acid-soluble (AS), and acid-insoluble (AI) fractions of suspended POC at various depths from a station in the northeast Pacific. We show that the $\Delta^{14} \mathrm{C}$ values of TLE and the AI fraction of deep suspended POC are lower than those of the AS fraction, which has been also observed for other sample types. It appears that the exchange of organic carbon among different carbon pools in addition to aging in a given carbon pool controls the $\Delta^{14} \mathrm{C}$ signatures of these organic fractions.

\section{Methods}

[5] Suspended POC samples were collected at Station M in the northeastern Pacific $\left(34^{\circ} 50^{\prime} \mathrm{N}, 123^{\circ} 00^{\prime} \mathrm{W}, 220 \mathrm{~km}\right.$ west of the central California coast, USA) during the PULSE-15 cruise in October 1992. About 600 to 2500 liters of seawater were filtered in-situ using Yentsch pumps through $0.8 \mu \mathrm{m}$ nominal pore diameter, quartz fiber filters (Whatman ultrapure QM-A, $142 \mathrm{~mm}$ diameter) that were pre-combusted at $550^{\circ} \mathrm{C}$. Each Yentsch pump was equipped with four filter holders and corresponding flow meters attached to a battery-operated water pump. Samples on filters were stored at $-20^{\circ} \mathrm{C}$ in glass Petri dishes wrapped in cleaned aluminum foil until analysis. The concentrations and radiocarbon and stable carbon isotope ratio $\left(\delta^{13} \mathrm{C}\right)$ results of bulk suspended POC for these samples were published previously [Druffel et al., 1996].

[6] Whole filters were dried in an oven at $50^{\circ} \mathrm{C}$ and used for separation of organic fractions. We followed the method described by Wang et al. [1998] for separation of organic fractions except that we did not separate amino acids and 

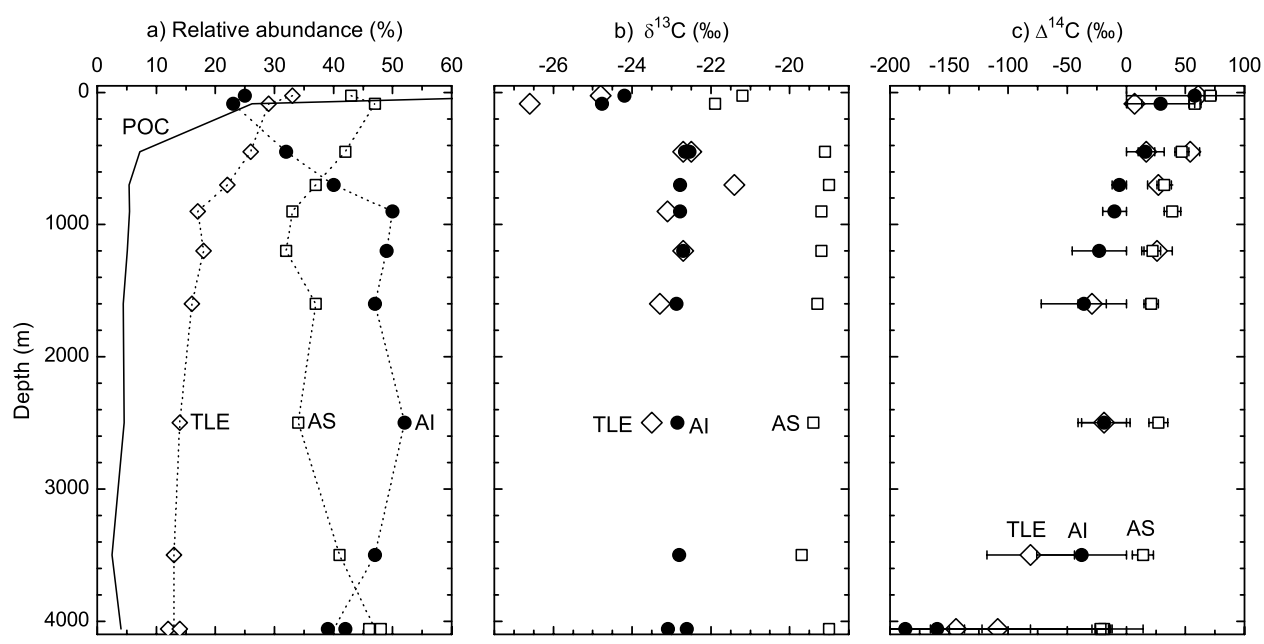

Figure 1. (a) Relative abundances of organic fractions of suspended POC [total lipid extract (TLE)-diamonds, acid soluble (AS)-squares, and acid insoluble (AI)-circles]. Relative abundance of each organic fraction is the ratio of the amount of each organic fraction to the sum of the three organic fractions. The solid line represents the concentration of bulk suspended POC in $\mu \mathrm{gC} / \mathrm{L}$ (note that it is plotted on the same x-axis) [Druffel et al., 1996]. Duplicate results are shown for the deepest sample. The uncertainty based on the duplicate results and our experience is less than $\pm 5 \%$. (b) The $\delta^{13} \mathrm{C}$ values of the organic fractions. The uncertainty is about $0.2 \%$. (c) The $\Delta^{14} \mathrm{C}$ values of the organic fractions.

carbohydrates. Briefly, each dried filter was ultrasonicated in a methylene chloride:methanol mixture (2:1 by volume) to obtain TLE. The dried residue including the filter was hydrolyzed with $6 \mathrm{~N} \mathrm{HCl}$ under $\mathrm{N}_{2}$ gas at $100^{\circ} \mathrm{C}$ for 19 hours to extract the acid-soluble fraction (AS). The AS fraction is expected to contain hydrolyzable amino acids, carbohydrates, amino sugars, and other hydrolyzable macromolecules. We chose to analyze the AS fraction without separating it further into amino acids and carbohydrates because previous work revealed that these two fractions in oceanic organic matter have similar $\Delta^{14} \mathrm{C}$ and $\delta^{13} \mathrm{C}$ values [Wang et al., 1998; Hwang and Druffel, 2003]. The residue remaining at the end of acid-hydrolysis was defined as the acid-insoluble fraction (AI). Each extracted organic fraction was combusted with cupric oxide and silver foil in an evacuated, closed quartz tube at $850^{\circ} \mathrm{C}$ for 2 hours. The volume of cryogenically purified $\mathrm{CO}_{2}$ gas was determined manometrically.

[7] Because whole filters were used for separation of organic fractions, we were not able to determine the recovery of each organic fraction. However, using POC content in a separate filter from the same pump after correction to account for different volumes of filtered seawater, we estimate total recovery to be about $64 \pm 7 \%$ $(\mathrm{n}=11)$. We believe that the actual recovery was higher than this value based on our test using standard material ( $>90 \%$ for cod liver oil and glutamic acid). Also, the separation scheme was stream-lined to minimize the loss of organic carbon.

[8] A split of $\mathrm{CO}_{2}$ gas was reduced to graphite on cobalt powder at $550{ }^{\circ} \mathrm{C}$ with $\mathrm{H}_{2}$ as a reducing agent. The $\Delta^{14} \mathrm{C}$ and $\delta^{13} \mathrm{C}$ values were measured at the Keck Carbon Cycle AMS Laboratory at the University of California, Irvine. The effect of blank carbon incorporated during isolation of the organic fractions on $\Delta{ }^{14} \mathrm{C}$ and $\delta^{13} \mathrm{C}$ results was corrected using the standard dilution method described by Hwang and Druffel [2005]. The correction of $\Delta^{14} \mathrm{C}$ results for TLE was larger $(20 \pm 13 \%)$ than that for AS $(<6 \%)$. The $\Delta^{14} \mathrm{C}$ results of AI were not blank-corrected because the amount of blank carbon was negligible compared to the sample sizes and the blank correction was expected to be within the measurement errors [Hwang and Druffel, 2005].

\section{Results and Discussion}

\subsection{Relative Abundances of Organic Fractions}

[9] The abundance of each organic fraction is reported with respect to its abundance relative to the sum of the three organic fractions. The abundances of the TLE and AS fractions decreased from the surface to $900 \mathrm{~m}$ depth, whereas that of the AI fraction increased with depth (Figure 1a and Table 1). Abundances of all three fractions were generally uniform below $900 \mathrm{~m}$ except at the two deepest depths (600 and 50 meters above bottom). Considering that most of the change in bulk suspended POC concentration occurs in the upper $1000 \mathrm{~m}$ (Figure 1a [Druffel et al., 1996, 1998], the loss of POC with depth appears to accompany apparent compositional change, although not proportionally. For example, the largest decrease in suspended POC concentration occurs between $25 \mathrm{~m}$ and $85 \mathrm{~m}$ depths (Figure 1a [Druffel et al., 1996]), where compositional change in this depth range is minor. Our results are consistent with the observation that processes in the mesopelagic zone (100-1000 m depth) are mainly responsible for alteration of suspended POC composition [Sheridan et al., 2002].

[10] The composition of suspended POC at $3500 \mathrm{~m}$ depth (600 $\mathrm{m}$ above bottom) is similar to that of sinking POC from $3450 \mathrm{~m}$ depth at the same location, where abundances of TLE and the AI fraction were about $10 \%$ and $45 \%$, respectively [Hwang and Druffel, 2003]. The composition of suspended POC and the change of composition with depth in the water column at Station $\mathrm{M}$ is similar to that observed for sinking POC at various depths in the Equatorial Pacific [Wakeham et al., 1997], although our definition 
Table 1. Relative Abundance, $\Delta^{14} \mathrm{C}$, and $\delta^{13} \mathrm{C}$ Values of the Organic Fractions of Suspended POC

\begin{tabular}{|c|c|c|c|c|c|c|c|c|c|}
\hline \multirow[b]{2}{*}{ Depth, m } & \multicolumn{3}{|c|}{ Total Lipid Extract } & \multicolumn{3}{|c|}{ Acid-Soluble } & \multicolumn{3}{|c|}{ Acid-Insoluble } \\
\hline & Relative Yield, \% & $\Delta^{14} \mathrm{C}, \%$ & $\delta^{13} \mathrm{C}, \%$ & Relative Yield, \% & $\Delta^{14} \mathrm{C}, \%$ & $\delta^{13} \mathrm{C}, \%$ & Relative Yield, \% & $\Delta^{14} \mathrm{C}, \%$ & $\delta^{13} \mathrm{C}, \% 0$ \\
\hline 25 & 33 & $61 \pm 10$ & -24.8 & 43 & $71 \pm 10$ & -21.2 & 25 & $58 \pm 10$ & $\overline{-24.2}$ \\
\hline 85 & 29 & $7 \pm 10$ & -26.6 & 47 & $58 \pm 10$ & -21.9 & 23 & $29 \pm 10$ & -24.8 \\
\hline 450 & & $54 \pm 10$ & -22.7 & & & & & & -22.6 \\
\hline 450 & 26 & $17 \pm 10$ & -22.5 & 42 & $47 \pm 10$ & -19.1 & 32 & $16 \pm 10$ & -22.7 \\
\hline 700 & 22 & $27 \pm 10$ & -21.4 & 37 & $32 \pm 10$ & -19.0 & 40 & $-6 \pm 10$ & -22.8 \\
\hline 900 & 17 & & -23.1 & 33 & $39 \pm 10$ & -19.2 & 50 & $-10 \pm 10$ & -22.8 \\
\hline 1200 & 18 & $26 \pm 13$ & -22.7 & 32 & $22 \pm 10$ & -19.2 & 49 & $-23 \pm 10$ & -22.7 \\
\hline 1600 & 16 & $-29 \pm 12$ & -23.3 & 37 & $21 \pm 10$ & -19.3 & 47 & $-36 \pm 10$ & -22.9 \\
\hline 2500 & 14 & $-19 \pm 22$ & -23.5 & 34 & $27 \pm 10$ & -19.4 & 52 & $-19 \pm 10$ & -22.9 \\
\hline 3600 & 13 & $-81 \pm 37$ & & 41 & $14 \pm 10$ & -19.7 & 47 & $-38 \pm 10$ & -22.8 \\
\hline 4060 & 12 & $-109 \pm 28$ & & 46 & $-19 \pm 10$ & -19.0 & 42 & $-160 \pm 10$ & -22.6 \\
\hline 4060 & 14 & $-144 \pm 22$ & & 48 & $-22 \pm 10$ & -19.0 & 39 & $-187 \pm 10$ & -23.1 \\
\hline
\end{tabular}

of TLE and AS fractions are not the same as Wakeham et al.'s lipids and the sum of amino acids and carbohydrates, respectively; our TLE and AS fractions likely contain components that cannot be characterized by chromatographic methods. The similarity between the sinking and suspended POC pools with respect to change in composition with depth indicates that either the two POC pools exchange material quickly [Bacon et al., 1985; Lee et al., 2004] or are controlled by similar processes. Although studies of individual amino acids and lipid compounds have shown that there are significant differences between sinking and suspended POC [Wakeham and Canuel, 1988; Wakeham and Lee, 1993; Sheridan et al., 2002], the differences do not appear prominent at the compound class level at Station M.

[11] Near the ocean bottom, abundances of the AS fraction increased and those of the AI fraction decreased slightly from those values in the upper water column. This may have been caused by processes in the bottom nepheloid layer, such as enhanced bacterial activity [Boetius et al., 2000].

\subsection{Stable Carbon Isotope Signatures of Organic Fractions}

[12] The $\delta^{13} \mathrm{C}$ values of the AS fraction were higher than those of TLE and AI fractions (Figure $1 \mathrm{~b}$ ). The $\delta^{13} \mathrm{C}$ values of the organic fractions appear to be determined mostly by physiological fractionation during their synthesis [Degens et al., 1968; Hayes, 2001]. In general, the $\delta^{13} \mathrm{C}$ values of the AI fraction were about 4\% lower than the AS fraction and similar to those of TLE (Figure 1b), which is consistent with those observed for sinking POC at $3450 \mathrm{~m}$ depth at Station M [Hwang and Druffel, 2003]. This pattern persisted in suspended POC samples throughout the water column regardless of sampling depth. In combination with the abundance results, the $\delta^{13} \mathrm{C}$ results suggest that the AI fraction of suspended POC contains a biogenic TLE-like component that accumulates with increasing depth, especially between the surface and $1000 \mathrm{~m}$ depth [Hwang et al., 2006].

\subsection{Radiocarbon Isotope Signatures of Organic Fractions}

[13] At $25 \mathrm{~m}$ depth, the $\Delta^{14} \mathrm{C}$ values of all organic fractions in suspended POC were similar to one another and to that of dissolved inorganic carbon (DIC) in the surface water (60 $\pm 20 \%$ [Masiello et al., 1998], Figure 1c). This indicates that all organic fractions contained bomb ${ }^{14} \mathrm{C}$ and were produced recently around the same time. However, the $\Delta^{14} \mathrm{C}$ values of the organic fractions from deep suspended POC were all lower than the surface water DIC value, indicating that these fractions contained ${ }^{14} \mathrm{C}$-depleted carbon in addition to contemporary, plankton-derived organic matter (Figure 1c). Except at $25 \mathrm{~m}$ depth, the $\Delta^{14} \mathrm{C}$ values of the AI fraction were lower than those of the AS fraction. The $\Delta^{14} \mathrm{C}$ values of TLE were also lower than those of the AS fraction with the exception of the mesopelagic zone.

[14] One potential source of ${ }^{14} \mathrm{C}$-depleted carbon is DOC sorbed onto suspended POC as previously suggested [Druffel and Williams, 1990]. However, this effect may have been exaggerated by enhanced DOC sorption onto POC during the filtration process. It is not well understood whether active sites on particles for DOC sorption are already saturated in the natural environment, in which case, filtration would not facilitate further sorption of DOC onto POC. If sorption is reversible [Wang and Lee, 1993; Komada and Reimers, 2001], existing organic coatings on particles may be replaced by DOC during filtration. Additionally, sorption of DOC onto filters is an artifact caused by filtration. Initial analysis of stacked, 142-mm diameter filters revealed that DOC sorption blank is less than $50 \mu \mathrm{gC}$, which is less than $3 \%$ of the sample amounts (J. Hwang and T. I. Eglinton, unpublished data, 2006). However, the effect of this blank carbon on the $\Delta^{14} \mathrm{C}$ measurement needs to be investigated further. Another potential source of ${ }^{14} \mathrm{C}$-depleted carbon is resuspended sediment that is laterally transported from the adjacent continental margin [Druffel et al., 1998; Sherrell et al., 1998]. Decreasing $\Delta{ }^{14} \mathrm{C}$ values of the organic fractions, especially TLE and the AI fraction, with increasing depth may indicate increasing influence of resuspended sediment. Sherrell et al.'s study using aluminum as a proxy of resuspended sediment suggested that contribution of resuspended sediment may reach farther up in the water column at Station M [Sherrell et al., 1998].

[15] The $\Delta^{14} \mathrm{C}$ values of organic fractions in various organic carbon pools from the northeast Pacific show several trends (Figure 2). The $\Delta{ }^{14} \mathrm{C}$ values of suspended POC and sinking POC are similar to or slightly lower than those of surface plankton and considerably higher than other organic carbon pools (DOC, sediment OC, river POC) indicating their short turnover times. The $\Delta^{14} \mathrm{C}$ 


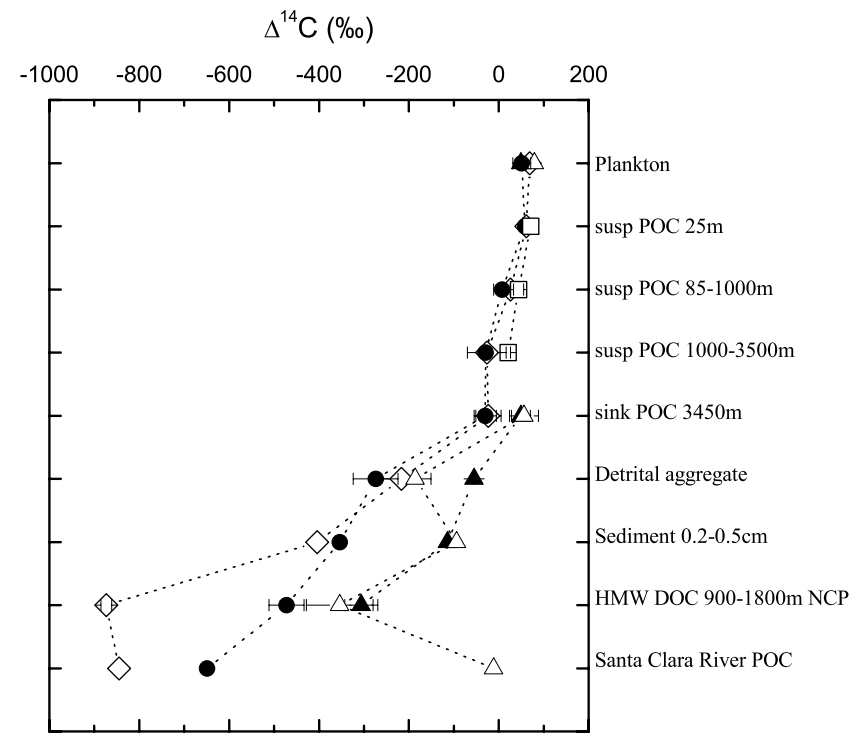

Figure 2. The $\Delta^{14} \mathrm{C}$ values of organic fractions in various organic carbon pools [TLE-diamonds, total hydrolyzable amino acids (THAA)-closed triangles, total hydrolyzable carbohydrates (TCHO)-open triangles, AS-squares, and AIcircles]. Error bars represent ranges of available data. Data for plankton, detrital aggregates, and sediment are from Wang et al. [1998], for HMW DOC from Loh et al. [2004], and for the Santa Clara River POC from Hwang et al. [2005]. Except HMW DOC and the Santa Clara River POC, all the other samples were from Station M.

values of organic fractions within the POC pools are similar to one another, in contrast to the other organic carbon pools. As was noted previously by Wang et al. [1996], the $\Delta^{14} \mathrm{C}$ values of the TLE and AI fractions are lower than the other organic fractions regardless of the type of sample (Figure 2). The ranges in $\Delta^{14} \mathrm{C}$ values among the organic fractions increase as the bulk $\Delta^{14} \mathrm{C}$ value decreases.

[16] The $\Delta{ }^{14} \mathrm{C}$ values of the AS fraction [including total hydrolyzable amino acids (THAA) and total hydrolyzable carbohydrates (TCHO) in other studies] of DOC and sediment that are lower than that of contemporary plankton, are likely due to aging in the reservoirs because there are no apparent sources of ${ }^{14} \mathrm{C}$-depleted $\mathrm{AS}$ fraction in other organic carbon pools besides heterotrophic incorporation of old DOC and DIC in the water column. However, the low $\Delta^{14} \mathrm{C}$ values of the TLE and AI fractions are likely due to a combination of aging within ocean water and input from ${ }^{14} \mathrm{C}$-depleted carbon sources. For example, the Santa Clara River, a small mountainous river in California, exports lipids eroded from sedimentary shale rocks to the ocean [Komada et al., 2005]. These ${ }^{14} \mathrm{C}$-depleted lipids can be further transported to the interior of the ocean by lateral advection [Hwang et al., 2005]. Of particular interest are the extremely low $\Delta^{14} \mathrm{C}$ values of TLE in HMW DOC [ Loh et al., 2004; Voparil et al., 2005]. Considering that lipids in DOC would be removed by adsorption to POC more selectively than other compound classes due to the high affinity to particles [Hedges, 1977; Henrichs, 1995], the turnover time of TLE is expected to be shorter than its ${ }^{14} \mathrm{C}$ age of over 16,000 years in the deep ocean [Loh et al.,
2004]. Contribution of natural hydrocarbons from oil seeps to DOC lipids has been reported for the southern California margin [Bauer et al., 1990] and the Gulf of Mexico [Wang et al., 2001]. However extremely low $\Delta^{14} \mathrm{C}$ values for TLE of HMW DOC were reported for both the north central Pacific and the Sargasso Sea [Loh et al., 2004], suggesting that the ancient source of lipids might not be confined to well-known hydrocarbon seeps. Other regions of the oceans will need to be examined to determine spatial variability of the $\Delta^{14} \mathrm{C}$ signature of TLE of HMW DOC, and understand the effect of a ${ }^{14} \mathrm{C}$-depleted organic carbon source.

[17] Acknowledgments. We thank Sheila Griffin for guidance in laboratory work and help with sampling, John Southon, Guaciara dos Santos, and Xiaomei Xu at the KCC AMS Laboratory for help with the carbon isotope measurements, Ken Smith and colleagues for help in sample collection and shared ship-time, Angie Dickens and Tim Eglinton's group for helpful discussions, and the captain and crew of the R/V New Horizon for their assistance and cooperation. This research was supported by NSF chemical oceanography program and Petroleum Research Fund of ACS.

\section{References}

Alldredge, A. L., and G. A. Jackson (1995), Aggregation in marine systems, Deep Sea Res., Part II, 42, $1-7$.

Bacon, M. P., C.-A. Huh, A. P. Fleer, and W. G. Deuser (1985), Seasonality in the flux of natural radionuclides and plutonium in the deep Sargasso Sea, Deep Sea Res., 32, 273-286.

Bauer, J. E., R. B. Spies, J. S. Vogel, D. E. Nelson, and J. R. Southon (1990), Radiocarbon evidence of fossil-carbon cycling in sediments of a nearshore hydrocarbon seep, Nature, 348, 230-232.

Boetius, A., B. Springer, and C. Petry (2000), Microbial activity and particulate matter in the benthic nepheloid layer (BNL) of the deep Arabian Sea, Deep Sea Res., Part II, 47, 2687-2706.

Boyd, P. W., et al. (1999), Transformation of biogenic particulates from the pelagic to the deep ocean realm, Deep Sea Res., Part II, 46, 2761-2792.

Chin, W.-C., M. V. Orellana, and P. Verdugo (1998), Spontaneous assembly of marine dissolved organic matter into polymer gel, Nature, 391, 568572 .

Degens, E. T., M. Behrendt, B. Gotthardt, and E. Reppmann (1968), Metabolic fractionation of carbon isotopes in marine plankton: II. Data on samples collected off the coasts of Peru and Ecuador, Deep Sea Res. $15,11-20$.

Druffel, E. R. M., and P. M. Williams (1990), Identification of a deep marine source of particulate organic carbon using bomb ${ }^{14} \mathrm{C}$, Nature, 347, $172-174$.

Druffel, E. R. M., J. E. Bauer, P. M. Williams, S. Griffin, and D. Wolgast (1996), Seasonal variability of particulate organic radiocarbon in the northeast Pacific Ocean, J. Geophys. Res., 101, 20,543-20,552.

Druffel, E. R. M., S. Griffin, J. E. Bauer, D. M. Wolgast, and X.-C. Wang (1998), Distribution of particulate organic carbon and radiocarbon in the water column from the upper slope to the abyssal NE Pacific Ocean, Deep Sea Res., Part II, 45, 667-687.

Eglinton, T. I., B. C. Benitez-Nelson, A. Pearson, A. P. McNichol, J. E. Bauer, and E. R. M. Druffel (1997), Variability in radiocarbon ages of individual organic compounds from marine sediments, Science, 277, $796-799$.

Guo, L., P. H. Santschi, L. A. Cifuentes, S. E. Trumbore, and J. Southon (1996), Cycling of high-molecular-weight dissolved organic matter in the Middle Atlantic Bight as revealed by carbon isotopic $\left({ }^{13} \mathrm{C}\right.$ and $\left.{ }^{14} \mathrm{C}\right)$ signatures, Limnol. Oceanogr., 41, 1242-1252.

Hayes, J. M. (2001), Fractionation of the isotopes of carbon and hydrogen in biosynthetic processes, in Stable Isotope Geochemistry, Rev. Mineral. Geochem., vol. 43, edited by J. W. Valley and D. R. Cole, pp. 225-278, Miner. Soc. of Am., Washington, D. C.

Hedges, J. I. (1977), The association of organic molecules with clay minerals in aqueous solutions, Geochim. Cosmochim. Acta, 41, 1119-1123.

Henrichs, S. M. (1995), Sedimentary organic matter preservation: An assessment and speculative synthesis-a comment, Mar. Chem., 49, $127-136$

Hwang, J., and E. R. M. Druffel (2003), Lipid-like material as the source of the uncharacterized organic carbon in the ocean?, Science, 299, 881884.

Hwang, J., and E. R. M. Druffel (2005), Blank correction for $\Delta^{14} \mathrm{C}$ measurements in organic compound classes of oceanic particulate matter, Radiocarbon, 47, 75-87. 
Hwang, J., E. R. M. Druffel, and T. Komada (2005), Transport of organic carbon from the California coast to the slope region: A study of $\Delta^{14} \mathrm{C}$ and $\delta^{13} \mathrm{C}$ signatures of organic compound classes, Global Biogeochem. Cycles, 19, GB2018, doi:10.1029/2004GB002422.

Hwang, J., E. R. M. Druffel, T. I. Eglinton, and D. J. Repeta (2006), Source(s) and cycling of the nonhydrolyzable organic fraction of oceanic particles, Geochim. Cosmochim. Acta, 70, 5162-5168.

Komada, T., and C. E. Reimers (2001), Resuspension-induced partitioning of organic carbon between solid and solution phases from a river-ocean transition, Mar. Chem., 76, 155-174.

Komada, T., E. R. M. Druffel, and J. Hwang (2005), Sedimentary rocks as sources of ancient organic carbon to the ocean: An investigation through $\triangle^{14} \mathrm{C}$ and $\delta^{13} \mathrm{C}$ signatures of organic compound classes, Global Biogeochem. Cycles, 19, GB2017, doi:10.1029/2004GB002347.

Lee, C., S. G. Wakeham, and C. Arnosti (2004), Particulate organic matter in the sea: The composition conundrum, Ambio, 33, 565-575.

Loh, A. N., J. E. Bauer, and E. R. M. Druffel (2004), Variable ageing and storage of dissolved organic components in the open ocean, Nature, 430 , $877-881$.

Masiello, C. A., E. R. M. Druffel, and J. E. Bauer (1998), Physical controls on dissolved inorganic radiocarbon variability in the California Current, Deep Sea Res., Part II, 45, 617-642.

McCave, I. N. (1984), Size spectra and aggregation of suspended particles in the deep ocean, Deep Sea Res., 31, 329-352.

Rau, G. H., D. M. Karl, and R. S. Carney (1986), Does inorganic carbon assimilation cause ${ }^{14} \mathrm{C}$ depletion in deep-sea organisms?, Deep Sea Res., $33,349-357$.

Sheridan, C. C., C. Lee, S. G. Wakeham, and J. K. B. Bishop (2002), Suspended particle organic composition and cycling in surface and midwaters of the equatorial Pacific Ocean, Deep Sea Res., Part I, 49, 1983 2008.

Sherrell, R. M., M. P. Field, and Y. Gao (1998), Temporal variability of suspended mass and composition in the northeast Pacific water column: relationships to sinking flux and lateral advection, Deep Sea Res., Part II, 45, 733-761.

Smith, D. C., M. Simon, A. L. Alldredge, and F. Azam (1992), Intense hydrolytic enzyme activity on marine aggregates and implications for rapid particle dissolution, Nature, 359, 139-142.

Stuiver, M., and H. A. Polach (1977), Reporting of ${ }^{14} \mathrm{C}$ data, Radiocarbon, $19,355-363$.
Verdugo, P., A. L. Alldredge, F. Azam, D. L. Kirchman, U. Passow, and P. H. Santschi (2004), The oceanic gel phase: A bridge in the DOM-POM continuum, Mar. Chem., 92, 67-85.

Voparil, I., M. McCarthy, and T. P. Guilderson (2005), Radiocarbon suggests independent cycling of biochemical constituents of ultrafiltered DOM, paper presented at 10th International Conference on Accelerator Mass Spectrometry, Univ. of Calif., Berkeley, Berkeley, Calif.

Wakeham, S. G., and E. A. Canuel (1988), Organic geochemistry of particulate matter in the eastern tropical North Pacific Ocean: Implications for particle dynamics, J. Mar. Res., 46, 183-213.

Wakeham, S. G., and C. Lee (1993), Production, transport, and alteration of particulate organic matter in the marine water column, in Organic Geochemistry, edited by M. H. Engel and S. A. Macko, pp. 145-169, Springer, New York.

Wakeham, S. G., C. Lee, J. I. Hedges, P. J. Hernes, and M. L. Peterson (1997), Molecular indicators of diagenetic status in marine organic matter, Geochim. Cosmochim. Acta, 61, 5363-5369.

Wang, X.-C., and C. Lee (1993), Adsorption and desorption of aliphatic amines, amino acids and acetate by clay minerals and marine sediments, Mar. Chem., 44, 1-23.

Wang, X.-C., E. Druffel, and C. Lee (1996), Radiocarbon in organic compound classes in particular organic matter and sediment in the deep northeast Pacific Ocean, Geophys. Res. Lett., 23, 3583-3586.

Wang, X.-C., E. R. M. Druffel, S. Griffin, C. Lee, and M. Kashgarian (1998), Radiocarbon studies of organic compound classes in plankton and sediment of the northeastern Pacific Ocean, Geochim. Cosmochim. Acta, 62, 1365-1378.

Wang, X.-C., R. F. Chen, J. Whelan, and L. Eglinton (2001), Contribution of "old" carbon from natural marine hydrocarbon seeps to sedimentary and dissolved organic carbon pools in the Gulf of Mexico, Geophys. Res. Lett., 28, 3313-3316.

E. R. M. Druffel, Department of Earth System Science, University of California, Irvine, Irvine, CA 92697, USA.

J. Hwang, Department of Marine Chemistry and Geochemistry, MS 4, Woods Hole Oceanographic Institution, Woods Hole, MA 02543, USA. (jhwang@whoi.edu) 